***This paper was accepted for publication in Psychology, Public Policy, and Law on June 5, 2020. This version may not replicate the final published version and should not be considered a final copy of record.***

\title{
Evaluating Selection for Sexually Violent Predator Commitment: A Comparison of Those Committed, Not Committed, and Nearly Committed
}

\author{
Anthony D. Perillo ${ }^{1}$, Cynthia Calkins², and Elizabeth L. Jeglic ${ }^{2}$ \\ ${ }^{1}$ Department of Psychology, Indiana University of Pennsylvania \\ ${ }^{2}$ Department of Psychology, John Jay College of Criminal Justice
}




\begin{abstract}
Author Note
This work was supported by the National Institute of Justice [2007-IJ-CX-0037, 2007]. Early results of this study were presented at the American Psychology-Law Society and Association for the Treatment of Sexual Abusers Conferences. Results of analysis of other portions of the dataset used in this study are published in Sexual Abuse, International Journal of Law and Psychiatry, and International Journal of Offender Therapy and Comparative Criminology.
\end{abstract}

The opinions, findings, and conclusions or recommendations expressed in this publication are those of the authors and do not necessarily reflect those of the Department of Justice. The authors wish to thank the New Jersey Department of Corrections and the New Jersey Department of Human Services for their support in providing access to files.

Correspondence concerning this article should be directed to Anthony D. Perillo, Department of Psychology, Indiana University of Pennsylvania, 1020 Oakland Avenue, Indiana, PA 15705, USA. Email: aperillo@iup.edu. Telephone: 1-724-357-2374. 


\begin{abstract}
We examined state-wide data of persons evaluated for Sexually Violent Predator (SVP) commitment and compared risk-relevant data of three groups: those committed as SVPS $(n=$ 374), those not recommended for commitment $(n=2,707)$, and those nearly committed (recommended for commitment but ultimately not committed; $n=117$ ). Consistent with legal language for SVP commitment, binary and multinomial regression analyses revealed risk scores predicted SVP commitment recommendations in addition to some historical factors (e.g., psychiatric history, never being married, prior sex offenses). For those recommended for commitment, prior sexual offenses predicted ultimate commitment. Those nearly committed had significantly higher sexual recidivism rates than others who were not committed; however, these recidivism rates were still low (11.5\%). Findings suggest evaluators' SVP decisions incorporate risk data and follow empirically supported trends; however, the observed recidivism rates of a subset of those SVP commitment appears to target suggests SVP commitment's potential for reducing sexual recidivism effectively and efficiently appears to have a low ceiling.
\end{abstract} Keywords: Sexually Violent Predator, sex offending, recidivism, civil commitment, risk assessment 


\section{Evaluating Selection for Sexually Violent Predator Commitment: A Comparison of Those Committed, Not Committed, and Nearly Committed}

Sexually Violent Predator (SVP) statutes permit the post-sentence civil commitment of persons convicted of a sex offense considered a heightened risk for reoffending. In the United States, 20 states and the federal government have enacted SVP legislation since 1990 (Calkins et al., 2014). Though statutory language differs across states, SVP commitment generally requires a history of sexual offending, a mental abnormality with evidence of volitional impairment, and a link between the mental abnormality and an elevated risk to commit future sexual violence (Kansas v. Hendricks, 1997; Mercado et al., 2006; Miller et al., 2005). New Jersey, for example, defines people subjected to SVP commitment (SVPs) as those with a history of sexual violence who "suffer from mental abnormalities or personality disorders which make them likely to engage in repeat acts of predatory sexual violence if not treated for their mental conditions" (N.J.S.A. 30:4-27.24 to -27.38). Since inception, however, SVP statutes have been controversial, including legal challenges to their constitutionality. In particular, legal arguments have been made that SVP civil commitment is in fact punitive (and not treatment) and, as such, violates protections against ex post facto laws and double jeopardy (Harris, 2015). Arguments about the punitiveness of SVP civil commitment even resurfaced during the COVID-19 pandemic, as reported rates of COVID-19 deaths at the New Jersey civil commitment facility exceed those of any U.S. prison (Smith, 2020).

Jurisdictions with SVP commitment laws are estimated to spend more than $\$ 500$ million annually to detain at least 4,658 persons (Associated Press, 2010; SOCCPN, 2014). For example, to civilly commit one person in New York State costs $\$ 175$, ooo per year-nearly three times the annual costs of incarceration (Bandler et al., 2017; Vera Institute, 2015). With legal referrals for SVP commitment significantly outpacing releases from commitment (e.g., Office of the Legislative Auditor- State of Minnesota, 2011), facilities face financial and resource strain (e.g., institutional space) on already strained budgets. Furthermore, SVP commitment laws seem to 
specifically target those at particularly high risk for reoffending without intervention (see the above language of the New Jersey law as an example), but the extent to which SVP commitment prevents sexual violence remains unclear. Given the legally justified objective of SVP commitment (treatment to increase public safety), high costs, and scant data on effectiveness, it is important to understand who is subjected to SVP commitment to assess consistency between critical parts of its mission and its practice.

\section{Trends in SVP Commitment Selection}

Much published research examining characteristics of SVPs reports demographics and characteristics of those held in SVP commitment programs (e.g., Meyer et al., 2003). Age is a key consideration since recidivism risk has been estimated to decline $4 \%$ per year as people with sex offending histories age (Hanson, 2002). SVPs are on average approximately in their midforties (Jumper et al., 2012), with some variability across jurisdictions. SVPs in Minnesota, for example, were found to be slightly younger at admission than those in Arizona (Becker et al., 2003; Janus \& Walbeck, 2000). Findings related to the victims of those committed as SVPs have been particularly variable; having adult, stranger victims (Janus \& Walbeck); having child victims (Levenson, 2004); and having both related and unrelated victims (Wrighten et al., 2015) have all been associated with SVP commitment. Levenson (2004) also found that SVPs were much more likely to have used a weapon during their index sex offense. A later study in New York found that factors suggestive of sexual deviance particularly predicted SVP commitment, including assessment of deviant sexual preferences or Pedophilia/Pedophilic Disorder, (Lu et al., 2015). Such assessments, however, have noted reliability limitations (see Perillo et al., 2014).

Comparison of actuarial risk scores across states suggests that risk scores associated with commitment also show variation among states (see Table 1). For example, reported actuarial risk scores of committed persons in Wisconsin are higher than those in Washington State (Elwood et al., 2010; Jackson \& Richards, 2007). Consistent with legislative intent, SVP risk scores have generally - though not always -- been found to be higher than the risk scores of 
those who were not committed. Levenson (2004) found average scores on risk measures for those ultimately committed in Florida to be significantly higher than those not committed, with Static-99 and MnSOST-R scores being robust predictors of selection for commitment (Levenson \& Morin, 2006). In Texas, incarcerated individuals who reached the point of having an SVP trial had significantly higher risk assessment scores than those not referred for SVP legal proceedings (Boccaccini et al., 2009). Findings from New York State, meanwhile, suggested once reviewed at a commitment hearing, actuarial risk scores did not differ for those ultimately committed or not committed (Lu et al., 2015).

\section{Outcomes Post-SVP Commitment}

Given that relatively few SVPs get released from commitment (Rappleye, 2012), a published systematic examination of recidivism rates of SVPS is lacking. At the time of their 2009 study, Boccaccini and colleagues reported that no one classified as an SVP in the Texas outpatient SVP program had recidivated with a sexually violent offense, though some had been returned to prison for other reasons. Neller and Petris (2013), who attempted to model the likely recidivism rates of those committed SVPS using data on published recidivism rates and screening procedures for SVP commitment, speculate that as many as 60\% of SVPs would have recidivated had they been released after their incarceration instead of committed.

In one of the first studies to report recidivism rates of released SVPs, DeClue and Rice (2016) reviewed SVP outcome data from Florida. Results noted five- and ten-year sexual recidivism rates among released SVPS at $9.2 \%$ and $13.1 \%$, respectively. Most recidivists were between age 30 and 49, but recidivism rates were relatively low even for these groups (11.5 to 15.9\%). Ten-year recidivism rates for SVPs were no higher than the ten-year recidivism rates for a random subset of persons convicted of sex offenses previously released from incarceration without being committed. Five-year recidivism rates for SVPS were higher than those of other released individuals (9.2\% vs. 5.3\%); however, the results suggest fairly low recidivism rates, with over $90 \%$ of released SVPs desisting through the first five years of release. 
Given logistical complications and lack of data for sexual recidivism post-SVP commitment, a few studies (Duwe 2014; Milloy, 2003; Milloy, 2007) have attempted to estimate recidivism rates of SVPs using a proxy: those reviewed for SVP civil commitment but ultimately not committed. Milloy (2007), who examined the six-year recidivism rates of 135 incarcerated individuals who were reviewed for civil commitment but where no petition was filed, found that $23 \%(n=31)$ were convicted of a new felony sex offense, and essentially half of those 135 individuals ( $n=67)$ were convicted of any type of new felony offense. Notably, the $23 \%$ (Milloy, 2007) sexual recidivism rate of this proxy sample is considerably higher than the $13.7 \%$ sexual recidivism rate observed by Hanson and Morton-Bourgon (2004) through their meta-analytic research. Indeed, sexual recidivism rates of other studies of similar focus were much lower. Of 261 persons reviewed for SVP commitment evaluations in Minnesota but ultimately not committed, 17 (6.5\%) sexually recidivated within four years (Duwe, 2014). A similar analysis in Florida revealed recidivism rates of those referred but not committed at 2-4\% (Montaldi, 2015).

Although reported recidivism rates for those not committed as SVPs have been relatively low in recent studies, questions remain about the potential recidivism rates of those committed as SVPs. On the one hand, critics of SVP commitment may contend that low recidivism rates across those reviewed for commitment (but not committed) suggest SVP commitment is superfluous and has minimal impact on public safety. On the other hand, one could argue that these low recidivism rates suggest SVP commitment is working because those at highest risk are detained (and those at lower risk are not).

An additional proxy for assessing SVP commitment may thus be to examine the recidivism rates of people nearly committed: those who were referred for commitment by legal decision-makers (e.g., district attorney) - and then recommended for commitment by an expert evaluator (e.g., psychiatrist or psychologist) - but were ultimately not committed. In fact, such focus may better reflect prospective recidivism rates of SVPs than actual recidivism rates of SVPS after release from commitment. Examination of recidivism among those committed, 
although useful, would be limited by the fact that SVPs often spend a decade or more committed; thus, they would be expected to show notable age-related declines in recidivism during their commitment (regardless of any effects of treatment while committed).

We might expect near commitment to be a rare occurrence, and indeed juries follow clinician recommendations on SVP commitment much more so when these recommendations support commitment (Elwood, 2019). Nonetheless, Montaldi (2015) reviewed data for 366 persons recommended for SVP commitment in Florida but who were nonetheless not committed after their prison sentence. Nearly nine percent (8.7\%) of these persons were later charged with a sex crime, suggesting higher recidivism rates than other people released after incarceration for a sex crime but presumably lower recidivism rates than would be expected (given the recommendation for indefinite commitment).

Given questions about how effective SVP commitment can actually be in reducing sexual violence, research must provide policymakers with findings that offer insight into efficient and efficacious focus of scarce resources. Examination of SVP commitment decision-making offers insight into the effectiveness of SVP commitment in multiple ways. One, such investigations can evaluate the extent that commitment decisions accurately target those at elevated risk by examining whether such decisions are consistent with factors empirically associated with recidivism risk (e.g., actuarial risk scores) rather than factors with no relationship to recidivism (e.g., race). Two, if SVP commitment decision-making were empirically based, comparisons of recidivism of non-committed individuals with the subset of nearly committed individuals would be expected to result in elevated recidivism rates among those nearly committed. Finally, review of nearly committed individuals offers a better proxy comparison to the potential recidivism rates of individuals considered for commitment than merely examining the broad scope of people released after incarceration for a sex crime.

\section{Study Aims}


Using a quasi-experimental design in a state-wide sample, the overall aim of the current study is to add to existing SVP literature by examining characteristics of those recommended for SVP commitment and recidivism rates of those recommended for commitment by expert evaluators but nonetheless not committed (i.e., nearly committed). First, we compared those committed as SVPS to those released from prison following their sentence (non-SVPs, which includes all those released regardless of whether they were referred and/or recommended for commitment) on a series of offense and risk factors. Using those factors that distinguished SVPS from non-SVPs, we used a series of logistic regressions to estimate the strength of the relationship between these factors and decisions to commit. Finally, we examined the sexual and non-sexual recidivism rates of nearly committed persons via Cox regressions to offer insight into the prospective recidivism rates of those being recommended for SVP commitment. Based on findings from SVP samples in other states, we anticipated that those who had been committed under SVP legislation would have the highest risk scores followed by those who were nearly committed and those that were not considered for SVP civil commitment. Further, we anticipated the group that was nearly committed would have higher rates of recidivism than the group not recommended for SVP commitment by an expert evaluator.

\section{Method}

\section{Sample}

As part of a broader Institutional Review Board-approved investigation of SVP commitment, archival data were extracted from the files of persons incarcerated for an index sexual offense and released from a New Jersey correctional facility between 1996 and $2007(N=$ 3,198). Figure 1 outlines the process and decisions surrounding SVP commitment proceedings in New Jersey that lead to persons being not committed, not committed but nearly committed, or SVP committed. Independent clinicians evaluate those soon to be released from incarceration that the district attorney has referred for an SVP commitment evaluation. Recommendations by these evaluators are considered by a state judge who makes a final decision on SVP 
commitment. From our sample, 2,824 persons were released from prison after completing their sentence and not subjected to commitment. Of these 2,824 persons, over 95 percent $(n=2,707)$ had not been recommended for commitment (our not committed group); however, the other 117 had indeed been recommended for commitment by an independent doctoral level (Ph.D., Psy.D., or M.D.) clinician but nonetheless did not have a final commitment petition filed in their name. These situations seemed to arise when there was some disagreement or discrepancy between experts and, ultimately, the judge did not feel the case for SVP commitment had been sufficiently supported by any experts recommending commitment. This group, all of whom were subsequently released upon completion of their prison sentence, constitutes our nearly committed subsample. The remaining 374 persons were recommended for commitment by doctoral level clinicians and then ultimately committed as SVPs (our SVP committed group).

\section{Figure 1}

Flowchart of New Jersey SVP Outcomes and Groups in Current Study

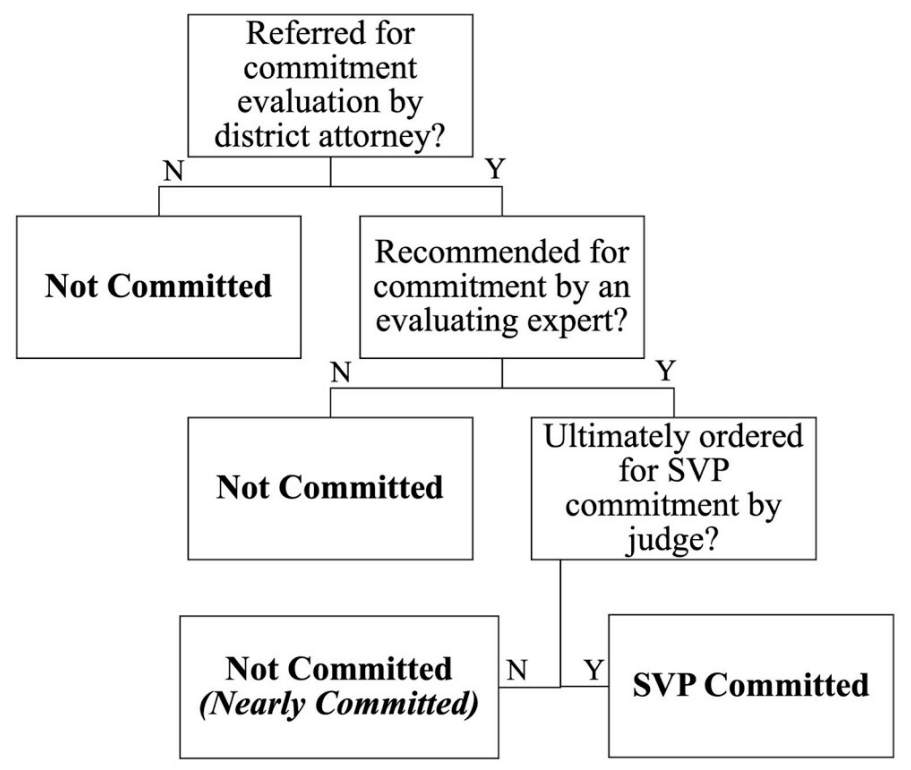

Note. The Nearly Committed group is a subsample of those not committed.

\section{Archival and Recidivism Data}

Information from state institutional files were coded from files by trained graduate students with a coding tool created by the second and third author of this paper. Data collected 
from files included demographics, offense history (e.g., past sexual and non-sexual offenses), institutional behavior, victim characteristics (e.g., age, gender), and static risk factors associated with sexual recidivism as measured by the Static-99 (Hanson \& Thornton, 1999) and the Minnesota Sex Offender Screening Tool-Revised (MnSOST-R; Epperson et al., 1998). Although these instruments have since been replaced in general clinical practice by the Static-99R and MnSOST-3, we chose to examine the original instruments scored at the time of SVP evaluation. Such focus more accurately reflects the consistency of SVP commitment decisions with empirically supported practice available at the time of evaluation.

Static-99. The Static-99 and its variants are the most commonly used sex offending risk assessment measures in the world (http://static99.org). Total scores on the Static-99 range from o to 12; these scores are then translated into risk levels ranging from o (lowest) to 6+ (highest). Hanson and Morton-Bourgon (2009) found that the Static-99 had predictive accuracy for both sexual and violent recidivism, and other studies have found significant correlations between scores on the Static-99 and recidivism (see Langton et al., 2007; Nunes et al., 2002). New Jersey State evaluators completed the assessments at intake. Item and total scores were transcribed for this study.

MnSOST-R. The MnSOST-R is an actuarial risk assessment measure consisting of 16 items: twelve that pertain to sex offending history (historical/static scale) and four that pertain to the person's institutional history (institutional/dynamic scale). Total scores on the scale range from -14 to +30 , and individuals are assigned to one of six risk levels based upon this score. Research results have suggested the MnSOST-R has served as a valid predictor of sexual recidivism (Hanson \& Morton-Bourgon, 2009). Although the MnSOST-R has not been validated for use with incest cases, for the purposes of this study item and total scores for the instrument were transcribed from the archival of all persons for which they were available, regardless of offense type. 
Recidivism Data. We collected follow-up information on new criminal convictions from two sources: the New Jersey State Police Computerized Criminal History System and the National Crime Information Center's Interstate Identification Unit. Follow-up time varied; on average released individuals were followed for 6.5 years, with recidivism determined by new convictions (including sexual and non-sexual crimes) that occurred both within and outside New Jersey. Recidivism rates reported in research use a number of different metrics. We chose reconviction as a middle-ground metric relative to broader (e.g., rearrests) and stricter (e.g., reconvictions) recidivism measures. Recidivism data were coded by trained graduate students with a coding tool created by the second and third author of this paper. All coding was reviewed by the second or third author of this study before being finalized for analysis.

\section{Analyses}

Group comparisons were made using chi-square and analysis of variance (ANOVA) techniques. Prediction of SVP decisions was assessed via binary and multinomial logistic regression. Cox regressions compared recidivism rates of the not committed and nearly committed groups while accounting for variability in time released.

\section{Results}

Those committed as SVPs were significantly older $\left(M_{\mathrm{age}}=42.33, \mathrm{SD}=11.55\right)$ than the entirety of those not committed $\left(M_{\mathrm{age}}=39.21, \mathrm{SD}=12.08\right)$ at the time of evaluation, $t(2,984)=$ $4.63, d=0.26$. A plurality of those committed as SVPs were White (48.9\%), followed by Black (40.9\%), Latino heritage (9.4\%), and another/unknown ethnicity (o.8\%). The entirety of those not committed (which includes the nearly committed group) were also predominantly White (40.6\%) or Black (36.2\%) but included more persons of Latino heritage (21.5\%). SVPs had significantly older victims than non-SVPs, $t(1,2853)=3.34, d=0.19$, and the victims of $S V P S$ were more likely to be male (23.2\%) and strangers (30.1\%) than the entirety of those not committed as SVPs (11.7\% and 12.1\%, respectively). 
Table 1

Comparison of SVP Static-99 and MnSOST-R Scores by State

\begin{tabular}{|c|c|c|c|c|}
\hline \multirow[b]{2}{*}{ State } & \multicolumn{2}{|c|}{ Static-99 } & \multicolumn{2}{|c|}{ MnSOST-R } \\
\hline & $\bar{M}$ & $S D$ & $M$ & $S D$ \\
\hline Washington ${ }^{\mathrm{a}}$ & 5.40 & 1.87 & 7.62 & 5.93 \\
\hline Wisconsin ${ }^{b}$ & 6.17 & 1.58 & 11.08 & 4.76 \\
\hline Florida $^{c}$ & 6.00 & 1.70 & 10.40 & 4.70 \\
\hline New York ${ }^{\mathrm{d}}$ & 5.59 & 2.05 & $\mathrm{n} / \mathrm{a}$ & $\mathrm{n} / \mathrm{a}$ \\
\hline Texas $^{\mathrm{e}}$ & 5.91 & 2.09 & 10.74 & 4.35 \\
\hline Nebraskaf & 3.50 & 1.88 & 3.76 & 5.75 \\
\hline New Jerseyg & & & & \\
\hline SVP Committed & 5.12 & 2.12 & 9.26 & 4.86 \\
\hline Nearly Committed & 4.32 & 2.00 & 7.08 & 5.37 \\
\hline
\end{tabular}

Notes. MnSOST-R - Minnesota Sex Offender Screening Tool- Revised. For New Jersey, Nearly Committed represents those recommended for commitment but ultimately not committed (released). All other figures represent persons ordered for commitment as SVPS in that state.

aJackson \& Richards (2007). bElwood, Doren, \& Thornton (2010). cLevenson (2004). d Lu, Freeman, \& Sandler (2015). eBoccaccini, Murrie, Caperton, \& Hawes (2009). fMcLawsen, Scalora, \& Darrow (2012). gCurrent study.

Across the sample, most had no history of sexual offending prior to the index offense (29.1\% with prior charges/convictions), although 68.4\% had a documented history of other offenses. Age at first sexual offense was widely variable $(M=30.1 ; \mathrm{SD}=28.3$; Median = 27.0; Range $=7$ to 77 ). Most persons (83.9\%) had exclusively female index victims, though $13.0 \%$ percent had exclusively male victims. Victims were most likely to be acquaintances $(51.2 \%)$, followed by extended or step family (25.3\%), strangers (21.4\%), and immediate family (10.1\%). SVPs in this sample scored within the moderate-high risk range on the Static-99 $(M=5.12)$ and within the high-risk range (Level 3) on the Mn-SOST-R $(M=9.26)$. For comparison with other states' SVP samples, see Table 1.

Almost one-third (32.8\%) had a documented psychiatric history, either prior to or during incarceration. Among those with prior psychiatric records, $10.0 \%(n=102)$ had a documented history of concerns related to sexual behavior or attraction, most commonly Pedophilia (5.0\%). The most common psychiatric concerns documented included mood or anxiety issues (45.1\%), substance abuse (35.8\%), psychosis (14.4\%), issues related to Attention Deficit/Hyperactivity 
Disorder (6.4\%), and Antisocial Personality Disorder (5.6\%). Figure 2 presents the most prominent diagnoses at the time of initial SVP evaluation. 41.0 percent of persons were diagnosed with a paraphilia (including Pedophilia or Paraphilia NOS) at the time of SVP evaluation, with Substance Use Disorders (32.3\%) and Antisocial Personality Disorder (28.4\%) the most commonly diagnosed non-paraphilic disorders.

Figure 2

Prevalence (\%) of Psychiatric Diagnoses during Initial SVP Evaluation

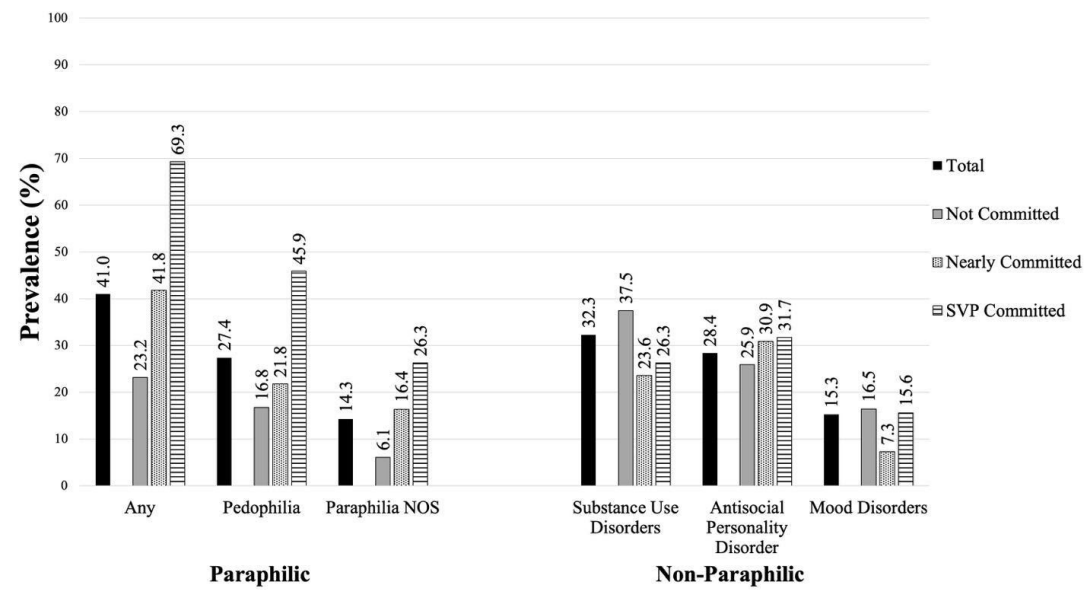

Notes. Statistics represent diagnostic rates in the initial SVP evaluation; several people received an additional evaluation. See Perillo et al. (2014) for notes on diagnostic inconsistencies. DSM-IV and DSMIV-TR diagnoses were used at the time of evaluations. Any Paraphilic Diagnosis includes diagnoses of Pedophilia and Paraphilia NOS as well as all other less common paraphilia diagnoses (e.g., Exhibitionism).

Table 2

Prevalence (\%) of Historical Risk Items and Demographic Information

\begin{tabular}{|l|r|r|r|r|r|}
\hline & $\begin{array}{c}\text { Not } \\
\text { Committed } \\
(n=2,707)\end{array}$ & $\begin{array}{c}\text { Nearly } \\
\text { Committed } \\
(n=117)\end{array}$ & $\begin{array}{c}\text { SVP } \\
\text { Committed } \\
(n=374)\end{array}$ & \multicolumn{1}{|c|}{$X^{2 a}$} & $V[95 \%$ CI $]$ \\
\hline Prior sex charges/ & & & & & \\
$\quad$ convictions & $\mathbf{2 0 . 4}$ & $\mathbf{5 5 . 9}$ & 79.9 & $\mathbf{5 9 6 . 6 8}$ & $\mathbf{. 3 1}[.29, .34]$ \\
Prior non-sex charges & $\mathbf{6 6 . 0}$ & $\mathbf{8 1 . 4}$ & $\mathbf{8 1 . 0}$ & $\mathbf{6 0 . 6 1}$ & $\mathbf{. 1 0}[.07, .12]$ \\
Juvenile crime: sex & $\mathbf{8 . 3}$ & $\mathbf{1 4 . 5}$ & $\mathbf{2 6 . 9}$ & $\mathbf{9 5 . 7 8}$ & $\mathbf{. 1 6}[.12, .19]$ \\
Juvenile crime: any & $\mathbf{2 1 . 8}$ & $\mathbf{4 1 . 7}$ & $\mathbf{4 5 . 4}$ & $\mathbf{1 2 7 . 7 8}$ & $\mathbf{. 1 5}[.12, .17]$ \\
Psychiatric history & $\mathbf{2 3 . 4}$ & $\mathbf{4 6 . 8}$ & $\mathbf{4 4 . 5}$ & $\mathbf{1 1 0 . 2 3}$ & $\mathbf{. 1 3}[.11, .16]$ \\
Use of weapon & 7.1 & $\mathbf{5 . 4}$ & $\mathbf{2 4 . 9}$ & $\mathbf{1 2 6 . 4 8}$ & $\mathbf{. 1 4}[.12, .17]$ \\
Threatened victim & $\mathbf{1 6 . 2}$ & $\mathbf{1 8 . 9}$ & $\mathbf{4 0 . 2}$ & $\mathbf{1 0 7 . 4 3}$ & $\mathbf{. 1 6}[.13, .19]$ \\
Immediate family & $\mathbf{1 0 . 9}$ & $\mathbf{4 . 5}$ & $\mathbf{8 . 4}$ & $\mathbf{6 . 4 8}$ & $\mathbf{. 0 5}[.00, .08]$ \\
Extended/Step family & $\mathbf{2 8 . 3}$ & $\mathbf{1 8 . 0}$ & $\mathbf{1 9 . 8}$ & $\mathbf{1 6 . 4 1}$ & $\mathbf{. 0 7}[.03, .11]$ \\
Acquaintance & 45.9 & 45.9 & 43.6 & 0.66 & $.01[.00, .04]$ \\
\hline
\end{tabular}




\begin{tabular}{|l|r|r|r|r|r|}
\hline Stranger & $\mathbf{1 1 . 5}$ & $\mathbf{3 1 . 5}$ & $\mathbf{3 2 . 2}$ & $\mathbf{1 3 6 . 9 9}$ & $\mathbf{. 2 1}[.17, .25]$ \\
Victim sex & & & & $\mathbf{5 8 . 7 0}$ & $\mathbf{. 1 0}[.07, .12]$ \\
Male & $\mathbf{1 1 . 3}$ & $\mathbf{1 9 . 6}$ & $\mathbf{2 3 . 2}$ & & \\
Female & 86.1 & 76.8 & 71.1 & & \\
Both & 2.6 & 3.6 & 5.7 & & \\
Ethnicity & & & & $\mathbf{4 3 . 3 4}$ & $\mathbf{. 0 8}[.05, .10]$ \\
White & 40.6 & 39.5 & 48.9 & & \\
Black & 35.7 & 47.4 & 40.9 & & \\
Latino & $\mathbf{2 1 . 9}$ & $\mathbf{1 1 . 4}$ & $\mathbf{9 . 4}$ & & \\
Other & 1.8 & 1.8 & 0.8 & & \\
Married & & & & $\mathbf{3 9 . 9 1}$ & $\mathbf{. 0 8}[\mathbf{. 0 5}, \mathbf{. 1 0}]$ \\
Never & 48.7 & 64.0 & 58.6 & & \\
Prior(s) & 17.7 & 16.7 & 21.9 & & \\
Yes & $\mathbf{3 3 . 5}$ & $\mathbf{1 9 . 3}$ & $\mathbf{1 9 . 6}$ & & \\
\hline
\end{tabular}

Note. Significant differences at $p<0.050$ are in bold.

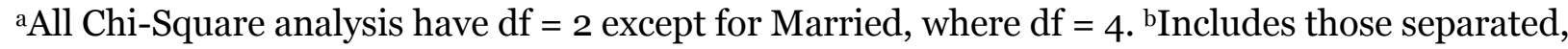
divorced, or widowed at time of index offense.

\section{Group Comparisons}

Compared to the entirety of those not committed, SVPS were more likely to have criminal histories prior to their index offense, both for sexual and non-sexual crimes. Chi-square analyses revealed that SVPS were more likely to have a prior history of sexual charges, non-sexual charges, and non-sexual violence, than the entirety of those not committed as SVPs. In addition, SVPs were more likely to have a juvenile history of both sexual and non-sexual offending. Psychiatric histories were also more common among SVPS. In regard to index offense characteristics, SVPs were more likely to have a male victim, a stranger victim, threatened their victim, and used a weapon during the offense.

Table 2 compares historical factors and index offense characteristics of those who were not committed, nearly committed, and SVP committed. Overall, similar results were found to those previously described. In particular, roughly 1 in 5 (20.4\%) of those not committed had a prior sexual offending history, just over half (55.9\%) of those nearly committed did, and roughly 4 in 5 (79.9\%) of those committed as SVPs had a prior sexual offending history. Follow-up chisquare analyses were conducted to specifically compare those nearly committed to those committed and others who were not committed (i.e., those never recommended for 
commitment). When compared to those neither committed nor recommended for commitment, those nearly committed were more likely to have a prior history of offenses (particularly sexual offenses), juvenile offenses, and psychiatric issues. Those nearly committed were also more likely to have male and/or stranger victims.

When comparing those committed as SVPs to only those nearly committed, SVPS were more likely to have a history of sexual offenses (including juvenile sexual offenses) and to have used violence during the index offense (i.e., used a weapon or other threatened the victim). Other differences previously found between those committed and those not committed, however, were not evident when SVPs were compared only to those nearly committed. No differences were found between these groups with regard to prior non-sexual offending history, psychiatric history, or victim characteristics.

Table 3 compares the mean ages at first offense, risk instrument scores, and age of victims for those not committed, nearly committed, and SVP committed. One-way analyses of variance (ANOVA) revealed significant differences in regard to age at first offense (sexual and non-sexual), victim age, and actuarial risk scores (Static-99 and MnSOST-R subscores). Posthoc Bonferroni tests revealed compared to those neither committed nor recommended for commitment (not committed), SVPs tended to have begun offending sexually, $d=0.59, p<.001$, 95\% CI [0.16, 1.02], and non-sexually, $d=0.32, p<.001,95 \%$ CI [-0.07, 0.72], at a younger age and to have offended against older victims, $d=0.20, p=.002,95 \% \mathrm{CI}[-0.21,0.61]$. In contrast, there were no differences between those committed as SVPs and those recommended for commitment but ultimately not committed (nearly committed) in regard to age at first sexual ( $p$ $=.276)$ and non-sexual ( $p=1.000)$ offense, victim age $(p=1.000)$, and MnSOST-R Institutional subscores $(p=.998)$. The largest differences appeared to be on static risk scores on the Static-99 ( $\mu^{2}=0.28$ ), and the MnSOST-R Historical subscale $\left(\mu^{2}=0.21\right)$. Those committed as SVPs had significantly higher scores on these static risk measures than both those not committed and those nearly committed (all $p<.001$ ). 
Table 3

Comparison of Group Means of Offense Characteristics and Risk Scores

\begin{tabular}{|c|c|c|c|c|c|c|c|c|c|}
\hline & \multicolumn{2}{|c|}{$\begin{array}{c}\text { Not } \\
\text { Committed }\end{array}$} & \multicolumn{2}{|c|}{$\begin{array}{c}\text { Nearly } \\
\text { Committed }\end{array}$} & \multicolumn{2}{|c|}{$\begin{array}{c}\text { SVP } \\
\text { Committed }\end{array}$} & \multicolumn{3}{|c|}{ ANOVA } \\
\hline & M & SD & M & SD & M & SD & $\mathrm{F}$ & $P$ & $\mu^{2}$ \\
\hline \multicolumn{10}{|l|}{ Age: $1^{\text {st }}$ offense } \\
\hline Sexuala & 30.23 & 11.31 & $\mathbf{2 5 \cdot 7 7}$ & 9.63 & 23.68 & 9.51 & 55.28 & $<.001$ & 0.04 \\
\hline Non-sexual b & 21.95 & 9.09 & 20.13 & 6.71 & 19.12 & 6.32 & 13.83 & $<.001$ & 0.01 \\
\hline \multicolumn{10}{|l|}{ MnSOST-R score } \\
\hline Historicalc & 0.64 & 5.05 & 8.36 & 11.68 & 9.45 & 4.81 & 308.08 & $<.001$ & 0.21 \\
\hline Institutionald & -0.78 & 2.82 & $-\mathbf{0 . 1 0}$ & 1.76 & -0.58 & 2.09 & $\mathbf{3 . 1 1}$ & .045 & $<0.01$ \\
\hline Static-99 totale & $\mathbf{2 . 3 3}$ & 1.63 & 4.54 & 1.95 & $5 \cdot 47$ & 1.91 & $\mathbf{4 6 4 \cdot 3 7}$ & $<.001$ & 0.28 \\
\hline Victim age $^{f}$ & 12.91 & 10.72 & 14.27 & 10.48 & 15.11 & 13.06 & 6.30 & .002 & $<0.01$ \\
\hline
\end{tabular}

Note. Significant differences at $p<0.050$ are in bold.

${ }^{a} \mathrm{df}=2,2,636 .{ }^{b} \mathrm{df}=2,2,008 .{ }^{c} \mathrm{df}=2,2,362 .{ }^{\mathrm{d}} \mathrm{df}=2,2,365 .{ }^{\mathrm{e}} \mathrm{df}=2,2,340 .{ }^{\mathrm{f}} \mathrm{df}=2,2,854$.

\section{Logistic Regression}

All variables found to be statistically significant through group comparison were entered into logistic regression analysis to identify predictors of SVP commitment decisions. Nominal variables with three or more categories (e.g., ethnicity) were recoded dichotomously for the presence of any categories for which there were significant group differences.

Predicting Clinician Commitment Recommendations. We conducted binary logistic regression analysis to identify predictors of clinicians' SVP commitment recommendations. The resulting model was statistically reliable when tested against a constantonly model, $X^{2}(20, N=709)=307.97, p<.001$. The model was robust overall, as the predictors provided a significant account for the variance among clinical recommendations (Nagelkerke $R^{2}$ $=.62$ ). Regression results (Table 4) suggested the strongest predictor of SVP commitment recommendations was a history of sex charges or convictions additional to the index offense; those with additional prior sex charges/convictions were 4.49 times more likely to be recommended for commitment. Higher risk scores (Static-99 and MnSOST-R Historical and Institutional scores) also predicted recommendations for commitment. Other significant predictors included never being married and having a male victim. 
Predicting Overall Commitment Outcomes. We conducted multinomial logistic regression to examine SVP commitment outcomes ordinally. We designated the nearly committed group as the reference group. The first set of regression results (consisting of the entirety of those not committed) examines predictors of being neither committed nor recommended for commitment (the not committed group). The second set of regression results (consisting of those recommended for commitment by clinicians) examines predictors of ultimately being committed as an SVP (the SVP committed group). Results are presented in Table 5. The resulting model was statistically reliable when tested against a constant-only model, $X^{2}(38, N=709)=391.11, p<.001$. The model was robust overall, as the predictors provided a significant account for the variance among SVP commitment outcomes (Nagelkerke $\left.R^{2}=.60\right)$

Among the entirety of those not committed as SVPs, regression results suggested higher Static-99 and MnSOST-R Historical risk scores decreased probability of membership in the not committed group. Inversely, higher risk scores were associated with higher probability that a clinician had recommended commitment (the nearly committed group). In addition to risk scores, psychiatric history was associated with higher probability that clinicians recommended commitment (the nearly committed group).

Among those that clinicians recommended for commitment (those nearly committed and those SVP committed), only prior sexual charges or convictions significantly predicted group membership, with those having prior sexual charges or convictions 5.64 times more likely to receive SVP commitment than those recommended for commitment but then not committed (nearly committed). Neither risk scores nor psychiatric history predicted ultimate SVP commitment for those that clinicians recommended for commitment.

\section{Table 4}

Binary Logistic Regression: Predicting Commitment Recommendations

\begin{tabular}{|llllllll}
\hline Predictor & B & S.E. & Wald & $p$ & Odds & Ratio & {$[95 \% \mathrm{CI}]$} \\
\hline
\end{tabular}




\begin{tabular}{|c|c|c|c|c|c|c|}
\hline Prior sex charges/convictions ${ }^{a}$ & 1.50 & 0.36 & 17.69 & $<.001$ & 4.49 & {$[2.23,9.04]$} \\
\hline Prior non-sex charges ${ }^{a}$ & 17.12 & $28,018.98$ & 0.00 & 1.000 & 100.00 & {$[0.00,>100.00]$} \\
\hline Juvenile crime: sex ${ }^{a}$ & 0.04 & 0.26 & 0.02 & .895 & 1.04 & {$[0.62,1.73]$} \\
\hline Juvenile crime: any a & 0.07 & 0.30 & 0.06 & .814 & 1.07 & {$[0.60,1.92]$} \\
\hline Psychiatric history ${ }^{\mathrm{a}}$ & 0.61 & 0.39 & 2.49 & .114 & 1.85 & {$[0.86,3.96]$} \\
\hline Use of weapon ${ }^{a}$ & 0.85 & 0.51 & 2.80 & .094 & 2.35 & {$[0.87,6.36]$} \\
\hline Threatened victima & 0.15 & 0.43 & 0.12 & .727 & 1.16 & {$[0.50,2.70]$} \\
\hline Immediate family victim $^{\mathrm{a}}$ & 0.49 & 0.66 & 0.54 & .463 & 1.63 & {$[0.44,5.99]$} \\
\hline Extended/Step-family victim ${ }^{\mathrm{a}}$ & 0.66 & 0.40 & 2.80 & .094 & 1.93 & {$[0.89,4.19]$} \\
\hline Stranger victim ${ }^{\mathrm{a}}$ & -0.43 & 0.41 & 1.08 & .298 & 0.65 & {$[0.29,1.46]$} \\
\hline Male victima & -0.86 & 0.41 & $4 \cdot 33$ & .038 & 0.43 & {$[0.19,0.95]$} \\
\hline Ethnicity: Latino ${ }^{\mathrm{a}}$ & -0.72 & 0.48 & 2.25 & .134 & 0.49 & {$[0.19,1.25]$} \\
\hline Married & 0.47 & 0.23 & 1.61 & .037 & 1.61 & {$[1.03,2.51]$} \\
\hline Age: $1^{\text {st }}$ offense, sexual & -0.02 & 0.02 & 0.71 & .400 & 0.99 & {$[0.94,1.02]$} \\
\hline Age: $1^{\text {st }}$ offense, any & 0.01 & 0.03 & 0.13 & .723 & 1.01 & {$[0.96,1.06]$} \\
\hline MnSOST-R Historical score & 0.21 & 0.04 & $\mathbf{2 9 . 7 7}$ & $<.001$ & 1.23 & {$[1.14,1.33]$} \\
\hline MnSOST-R Institutional score & 0.19 & 0.09 & 4.70 & .030 & 1.21 & {$[1.02,1.43]$} \\
\hline Static-99 score & 0.40 & 0.11 & 13.05 & $<.001$ & 1.49 & {$[1.20,1.84]$} \\
\hline Victim age & $<0.00$ & 0.01 & 0.03 & .863 & 1.00 & {$[0.98,1.03]$} \\
\hline
\end{tabular}

Notes. Odds ratios refer to the likelihood of being recommended for commitment (includes both Committed and Nearly Committed groups). Significant predictors at $p<0.050$ are in bold.

${ }^{a}$ Categorical variable. Variable was coded dichotomously for its presence $(\mathrm{o}=\mathrm{no}, 1=\mathrm{yes})$.

Table 5

Multinomial Logistic Regression: Predicting SVP Decisions

\begin{tabular}{|c|c|c|c|c|c|c|}
\hline Predictor & B & S.E. & Wald & $p$ & $\begin{array}{l}\text { Odds } \\
\text { Ratio }\end{array}$ & {$[95 \% \mathrm{CI}]$} \\
\hline Prior sex charges/convictions ${ }^{a}$ & -0.35 & 0.43 & 0.66 & .415 & 0.70 & {$[0.30,1.64]$} \\
\hline Prior non-sex charges ${ }^{a}$ & -12.29 & $1,160.56$ & 0.00 & .992 & $<0.00$ & {$[<0.00,>100.00]$} \\
\hline Juvenile crime: sex $^{\mathrm{a}}$ & 0.20 & 0.36 & 0.30 & .586 & 1.22 & {$[0.60,2.47]$} \\
\hline Juvenile crime: any ${ }^{a}$ & -0.11 & 0.39 & 0.08 & .785 & 0.90 & {$[0.42,1,94]$} \\
\hline Psychiatric history ${ }^{a}$ & -0.89 & 0.36 & 6.03 & .014 & 0.41 & {$[0.20,0.84]$} \\
\hline Use of weapon ${ }^{a}$ & 9.74 & 31.07 & 0.98 & .754 & 1.64 & {$[0.25,10.96]$} \\
\hline Threatened victim ${ }^{\mathrm{a}}$ & 0.00 & 0.00 & 1.96 & .161 & 1.00 & {$[1.00,1.02]$} \\
\hline Immediate family victim $^{\mathrm{a}}$ & -0.05 & 0.88 & 0.03 & .957 & 0.95 & {$[0.17,5.33]$} \\
\hline Extended/Step-family victim ${ }^{a}$ & -0.39 & 0.50 & 0.60 & .439 & 0.68 & {$[0.26,1.81]$} \\
\hline Stranger victim $^{\mathrm{a}}$ & 0.72 & 0.50 & 0.21 & .885 & 1.07 & {$[0.41,2.84]$} \\
\hline Male victim $^{\mathrm{a}}$ & -0.20 & 0.53 & 0.14 & .709 & 0.82 & {$[0.29,2.32]$} \\
\hline Ethnicity: Latino ${ }^{\mathrm{a}}$ & 0.61 & 0.59 & 1.06 & .303 & 1.84 & {$[0.58,5.89]$} \\
\hline Married $^{\mathrm{a}}$ & -0.26 & 0.29 & 0.82 & .365 & 0.77 & {$[0.44,1.36]$} \\
\hline Age: $1^{\text {st }}$ offense, sexual & 0.05 & 0.03 & 2.19 & .139 & 1.05 & {$[0.99,1.11]$} \\
\hline Age: $1^{\text {st }}$ offense, any & -0.06 & 0.03 & $\mathbf{3 . 8 7}$ & .049 & 0.94 & {$[0.88,1.00]$} \\
\hline MnSOST-R Historical score & -0.23 & 0.04 & 29.81 & $<.001$ & 0.79 & {$[0.73,0.86]$} \\
\hline MnSOST-R Institutional score & -0.17 & 0.10 & 2.62 & .106 & 0.85 & {$[0.69,1.04]$} \\
\hline Static-99 score & $-\mathbf{0 . 3 0}$ & $\mathbf{0 . 1 3}$ & $5 \cdot 35$ & .021 & 0.74 & {$[0.57,0.96]$} \\
\hline Victim age & -0.01 & 0.02 & 0.70 & .404 & 0.99 & {$[0.96,1.02]$} \\
\hline
\end{tabular}


SVP Committed

\begin{tabular}{|c|c|c|c|c|c|c|}
\hline $\begin{array}{l}\text { Prior sex } \\
\text { charges/convictions }\end{array}$ & 1.73 & 0.54 & 10.29 & .001 & 5.64 & {$[1.96,16.24]$} \\
\hline Prior non-sex charges ${ }^{a}$ & -1.72 & 0.00 & 0.00 & .992 & $<0.00$ & {$[<0.00,>100.00]$} \\
\hline Juvenile crime: sex & 0.28 & 0.38 & 0.54 & .464 & 1.32 & {$[0.63,2.77]$} \\
\hline Juvenile crime: any ${ }^{a}$ & 0.08 & 0.43 & 0.03 & .860 & 1.08 & {$[0.46,2.52]$} \\
\hline Psychiatric historya & -0.75 & 0.40 & 3.43 & .064 & 0.48 & {$[0.22,1.04]$} \\
\hline Use of weapon ${ }^{a}$ & 0.97 & 31.07 & 0.98 & .754 & 1.64 & {$[0.25,10.96]$} \\
\hline Threatened victima & 1.17 & 0.63 & 3.40 & .065 & 3.21 & {$[0.93,11.11]$} \\
\hline Immediate family victim $^{\mathrm{a}}$ & 0.79 & 0.95 & 0.68 & .410 & 2.12 & {$[0.34,14.18]$} \\
\hline Extended/Step-family victim ${ }^{\mathrm{a}}$ & 0.37 & 0.56 & 0.43 & .511 & 1.44 & {$[0.48,4.33]$} \\
\hline Stranger victim $^{\mathrm{a}}$ & -0.29 & 0.54 & 0.29 & .591 & 0.75 & {$[0.26,2.15]$} \\
\hline Male victim ${ }^{\mathrm{a}}$ & 0.37 & 0.56 & 0.45 & .505 & 1.45 & {$[0.49,4.33]$} \\
\hline Ethnicity: Latino ${ }^{\mathrm{a}}$ & -0.24 & 0.73 & 0.11 & .742 & 0.79 & {$[0.19,3.30]$} \\
\hline Married $^{\text {a }}$ & 0.34 & 0.31 & 1.15 & .283 & 1.40 & {$[0.76,2.59]$} \\
\hline Age: $1^{\text {st }}$ offense, sexual & 0.02 & 0.03 & 0.29 & .590 & 1.02 & {$[0.95,1.09]$} \\
\hline Age: $1^{\text {st }}$ offense, any & -0.05 & 0.04 & 1.97 & .160 & 0.95 & {$[0.88,1.02]$} \\
\hline MnSOST-R Historical score & -0.02 & 0.04 & 0.20 & .653 & 0.98 & {$[0.91,1.06]$} \\
\hline MnSOST-R Institutional score & 0.04 & 0.11 & 0.13 & .718 & 1.04 & {$[0.83,1.30]$} \\
\hline Static-99 score & 0.19 & 0.14 & 1.80 & .180 & 1.21 & {$[0.92,1.61]$} \\
\hline Victim age & 0.00 & 0.02 & 0.10 & .750 & 1.01 & {$[0.98,1.04]$} \\
\hline
\end{tabular}

Notes. The reference group is Nearly Committed. Odds ratios refer to the likelihood of membership in the comparison group (Not Committed in the first comparison; SVP Committed in the second comparison) for each 1-point increase in the predictor variable. Odds ratios above 1.00 indicate increased likelihood of membership in the comparison group. For the Not Committed comparisons, odds ratios below 1.00 indicate increased likelihood of being Nearly Committed (i.e., decreased likelihood of being in the Not Committed group) when the predictor is present (or for each 1-point increase for linear predictors). Significant predictors at $p<0.050$ are in bold.

${ }^{\mathrm{a} C a t e g o r i c a l ~ v a r i a b l e . ~ V a r i a b l e ~ w a s ~ c o d e d ~ d i c h o t o m o u s l y ~ f o r ~ i t s ~ p r e s e n c e ~}(\mathrm{o}=\mathrm{no}, 1=\mathrm{yes})$.

\section{Recidivism}

For the current study, recidivism was defined as a conviction following release for the sexual offense for which they were incarcerated at the time of data collection. Convictions may include those for another sexual offense, a non-sexual criminal offense, or a parole violation. At the time of data collection from the NJDOC (2007-2009), no individuals in New Jersey had been released from SVP commitment. At the time of analysis (2017), we had confirmed 82 individuals had been discharged from commitment in New Jersey following treatment completion; however, insufficient follow-up times limit our ability to reliably analyze recidivism and compare to the non-committed samples. As such, only those not committed as SVPs ( $n=$ 2,433) were included in the recidivism analysis. 
The general recidivism rate of our sample was 43.5\% $(n=968)$, meaning that about twofifths of those released were convicted of any new offense (sexual or non-sexual) or a parole violation (Table 6). The sexual recidivism rate was $4.2 \%$, as 103 individuals released during the period of our study were reconvicted for another sex offense. Although this sexual recidivism rate is considerably lower than those rates reported by others (such as the sexual recidivism rate of 13.4\% reported in Hanson and Bussière's 1998 meta-analysis), differences are likely at least partly attributed to the conservative criteria used to measure recidivism (i.e., reconviction rather than rearrest) in the current study. Regarding other types of recidivism, 6.o\% of released individuals were convicted of a follow-up violent offense, and 14.3\% were convicted of another non-violent offense. Additionally, 10.3\% were convicted of a parole violation, and $11.9 \%$ were convicted of failing to register as a sex offender.

Table 6

Prevalence of Recidivism (\%), Arranged by Offense Type

\begin{tabular}{|l|c|c|}
\hline Recidivism Type & $\begin{array}{c}\text { Not Committed } \\
(n=2,707)\end{array}$ & $\begin{array}{c}\text { Nearly Committed } \\
(n=117)\end{array}$ \\
\hline Sexual & & \\
Violent & 5.0 & 11.5 \\
Non-violent & 5.8 & 11.4 \\
Failure to register & 16.2 & 24.1 \\
Parole violation & 13.8 & 13.9 \\
Any & 11.8 & 15.2 \\
\hline
\end{tabular}

Notes. We defined recidivism as a conviction following release for the index sexual offense. For persons with multiple follow-up convictions, only the first conviction was coded as recidivism.

Table $7 \mathbf{a}$ Cox Regressions for Those Nearly Committed and Recidivism

\begin{tabular}{|c|c|c|c|c|c|c|}
\hline Recidivism Type & B & S.E. & Wald & $p$ & Hazard ratio & {$[95 \% \mathrm{CI}]$} \\
\hline Sexual & 0.81 & 0.39 & 4.20 & .040 & 2.24 & {$[1.04,4.86]$} \\
\hline Violent & 0.95 & 0.35 & 7.25 & .007 & $\mathbf{2 . 5 7}$ & {$[1.29,5.12]$} \\
\hline Non-Violent & 0.58 & 0.25 & 5.44 & .020 & 1.78 & {$[1.01,2.89]$} \\
\hline Failure to register & 0.07 & 0.33 & 0.04 & .839 & 1.07 & {$[0.56,2.04]$} \\
\hline Parole violation & 0.38 & 0.31 & 1.53 & .216 & 1.47 & {$[0.80,2.69]$} \\
\hline Any & 0.51 & $\mathbf{0 . 1 7}$ & 9.30 & .002 & $\mathbf{1 . 6 7}$ & {$[1.20,2.32]$} \\
\hline
\end{tabular}


Table $7 \mathbf{b}$

Cox Regressions for Those Nearly Committed and Recidivism with Static-99 Scores

\begin{tabular}{|c|c|c|c|c|c|c|}
\hline Recidivism Type & $\mathrm{B}$ & S.E. & Wald & $p$ & Hazard ratio & {$[95 \% \mathrm{CI}]$} \\
\hline \multicolumn{7}{|l|}{ Sexual } \\
\hline Nearly committed & -0.18 & 0.45 & 0.16 & .693 & 0.84 & {$[0.35,2.02$} \\
\hline Static-99 score & 0.34 & 0.06 & $\mathbf{3 7 . 2 5}$ & $<.001$ & 1.41 & {$[1.26,1.57$} \\
\hline Violent & & & & & & \\
\hline Nearly committed & 0.11 & 0.40 & 0.08 & .777 & 1.12 & {$[0.51,2.47$} \\
\hline $\begin{array}{l}\text { Static-99 score } \\
\text { Non-Violent }\end{array}$ & $\mathbf{0 . 3 1}$ & 0.06 & 31.00 & $<.001$ & 1.36 & {$[1.22,1.52$} \\
\hline Nearly committed & -0.16 & 0.29 & 0.31 & .579 & 0.85 & {$[0.48,1.51$} \\
\hline Static-99 score & 0.22 & 0.04 & 40.16 & $<.001$ & 1.25 & {$[1.16,1.33$} \\
\hline Failure to register & & & & & & \\
\hline Nearly committed & -0.45 & 0.38 & 1.42 & .234 & 0.64 & {$[0.30 .1 .34$} \\
\hline Static-99 score & $\mathbf{0 . 1 1}$ & 0.04 & 8.46 & .004 & $\mathbf{1 . 1 1}$ & {$[1.04,1.21$} \\
\hline Parole violation & & & & & & \\
\hline Nearly committed & -0.11 & 0.34 & 0.11 & .742 & 0.90 & {$[0.46,1.73$} \\
\hline Static-99 score & 0.14 & 0.04 & 13.44 & $<.001$ & 1.15 & {$[1.07,1.24$} \\
\hline Any & & & & & & \\
\hline Nearly committed & -0.02 & 0.19 & 0.02 & .899 & 0.98 & {$[0.67,1.42$} \\
\hline Static-99 score & $\mathbf{0 . 1 7}$ & 0.02 & 53.81 & $<.001$ & 1.18 & {$[1.13,1.24$} \\
\hline
\end{tabular}

Notes. We defined recidivism as a conviction following release for the index sexual offense. For persons with multiple follow-up convictions, only the first conviction was coded as recidivism. Significant predictors at $p<0.050$ are in bold.

To test associations between being recommended for commitment and subsequent recidivism, a series of Cox regressions were analyzed. We analyzed Cox regressions to account for variability in the length of time released (i.e., duration of opportunity to recidivate). We completed each regression in two blocks: the first block included commitment recommendation (i.e., our not committed vs. nearly committed groups) as the lone predictor (Table 7a), and the second block added Static-99 score as an additional predictor (Table 7b). Hazard ratios represent the probability of recidivism for those recommended for commitment (nearly committed) relative to those neither committed nor recommended for commitment.

Broadly speaking, those who were nearly committed were 1.67 times more likely to be convicted of a follow-up offense (any), 2.57 times more likely to violently recidivate, and 2.24 times more likely to sexually recidivate after release. No differences in probability of follow-up convictions for non-violent offenses, parole violations, or failure to register were observed. As 
noted in the multinomial logistic regression results, Static-99 scores predicted being recommended for commitment among those who were not committed (higher risk scores predicting being nearly committed). To clarify the extent that recidivism differences among these groups was more a product of overarching recidivism risk, Table $7 \mathrm{~b}$ includes Static-99 risk score as an additional predictor. After accounting for Static-99 scores, clinician recommendations no longer significantly predicted recidivism at any level. Instead, Static-99 scores uniquely and significantly predicted recidivism at every level of analysis, with higher risk scores associated with higher recidivism rates.

\section{Discussion}

The current study examined the characteristics and recidivism rates for a sample of potential SVPs, thereby allowing for the continued evaluation of SVP commitment within an overall model of sexual violence prevention. That is, we examined stages of SVP commitment decisions (referrals, recommendations, and ultimate orders for commitment) and aimed to answer who is recommended for SVP commitment and what characteristics evaluators rely upon to make recommendations for SVP commitment. Further, and perhaps most important in evaluating SVP commitment, we examined persons nearly committed as SVPs to reflect potential recidivism rates of the body of those recommended for SVP commitment. Taken together, the current study examines the extent that current practices in SVP commitment truly focus on those at most risk to commit future sexual violence and the potential capacity for SVP commitment to prevent sexual violence.

\section{Clinician Recommendations for SVP Commitment}

We found persons ultimately committed as SVPS to be higher risk on actuarial risk instruments than those not committed. SVPS in our sample tended to have more victims, have a juvenile record, and have a psychiatric history relative to those not committed. Further, the SVPs in our sample had significantly higher actuarial risk scores. 
In New Jersey, an $S V P$ is statutorily defined as one who has a history of sexual offenses and who "suffers from a mental abnormality or personality disorder that makes the person likely to engage in acts of sexual violence if not confined in a secure treatment facility for control, care, and treatment." The decisions in practice (both the recommendations by clinicians and ultimate orders for commitment by the state) appear overall to be congruent with these guidelines. We found that among the entirety of those not committed as SVPs, those recommended for SVP commitment (nearly committed) had higher static risk scores and were more likely to have a psychiatric history than others who were not committed. These predictors are relevant to both general prongs of SVP commitment: elevated recidivism risk and mental abnormality. The key difference between those recommended for commitment who were or were not committed was a record of sexual offenses beyond the index offense, as those with prior sexual charges or convictions were over 5 times more likely to be committed.

Overall, these results suggest evaluator recommendations for commitment generally adhere to state criteria for SVP commitment and are consistent with the empirical literature on sexual recidivism risk. It thus appears that SVP commitment in practice is consistent-at least at the selection stage-in its mission of targeting those at elevated risk for future sexual violence, while final judicial determinations for commitment may be further influenced by a record of prior sexual offending (beyond the index offense).

\section{Prospective Recidivism of Those Committed}

We attempted to gain insight into prospective recidivism rates of those to whom SVP commitment laws appear to apply by using a proxy sample of those who were recommended for commitment but nonetheless released. Such analysis also allows us to infer the potential capacity of SVP commitment to reduce recidivism risk among those who appear to meet the legal definition of an SVP; the higher the recidivism rates for those nearly committed, the higher the likely capacity for SVP commitment to have an impact on recidivism. Although sexual reconviction rates of those nearly committed as SVPS were more than double (11.5\%) those of 
the general sample (5.0\%), it is notable also that these rates of recidivism are still relatively low. Nonetheless, we found those nearly committed were indeed more likely to recidivate, particularly for more serious offenses (sexual and violent offenses). Indeed, offenses for which those nearly committed had no higher likelihood of recidivism were generally those less directly relevant to sexual risk assessment.

Recidivism results again suggest clinicians are effectively identifying those that better fit the criteria and aims of SVP commitment, as those recommended for commitment but nonetheless released were over twice as likely to sexually recidivate than others who were released. Given that, among those released, higher risk scores predicted who had been recommended for commitment (nearly committed), we examined the extent that recidivism differences for those recommended for commitment were more directly explained by their higher risk scores (which indeed appears to be the case). These results seem to clarify why among those released, elevated recidivism rates fell generally in line with clinician recommendations for commitment. Specifically, it appears that among those who were not committed, clinicians indirectly identified those at increased risk to reoffend more so as a product of their elevated risk scores rather than specifically identifying those individuals through any number of other, potentially subjective means.

On the one hand, given that rates of recidivism for this nearly committed group are considerably (both in a practical and statistical sense) higher than others in the not committed group, this finding suggests that those being targeted for SVP commitment are in fact those most likely to recidivate. On the other hand, relative rates of sexual recidivism in our sample are still comparatively low and suggest that, most likely, the majority of committed SVPS would desist from sexual offending without commitment, despite elevated risk scores. These comparatively low recidivism rates of those nearly committed (with $88.5 \%$ not recidivating) arguably suggest SVP commitment's ability to reduce sexual recidivism effectively and efficiently 
has a low ceiling, as commitment and/or treatment's potential impact on recidivism would be limited by the already low rates of recidivism.

\section{Implications for Effectiveness and Efficiency of SVP Commitment}

The most widely cited meta-analytic findings (Hanson \& Morton-Bourgon, 2004; Hanson \& Morton-Bourgon, 2009) have reported sexual recidivism rates between $13-14 \%$ for persons with a sexual offending history with an average follow-up time of 5-6 years, considerably higher than that for our sample of released individuals (though the stringent criteria of reconviction in the current study likely contributes to this discrepancy). Although Milloy (2007) found higher rates of sexual reoffense (23\%) in her sample of nearly committed individuals, fewer than 1 out of 4 recidivated. Given the high cost of commitment and the fact that essentially $95 \%$ of sexual offenses are committed by first-time offending parties rather than those previously convicted of sex offenses (Sandler et al., 2008), more cost-effective alternatives to SVP commitment (e.g., community-based treatment) are likely to be as effective (if not more so) in reducing sexual violence, offering a greater return on investment (Jeglic \& Calkins, 2016).

Although the current study includes no economic data and thus no specific costeffectiveness data, the fact that $88.5 \%$ of persons targeted for SVP commitment (the nearly committed group) did not reoffend suggests SVP commitment could only prevent additional sexual violence for a small minority of those committed. Such findings are consistent with prior conclusions that, given the narrow scope of SVP commitment (in terms of those targeted and the types of offenses prevented) relative to the resources we devote to it, SVP commitment is arguably best summarized as a well-intended practice that unfortunately offers little return on investment (Perillo \& Jeglic, 2013). Findings of this study suggest that clinicians are generally identifying those at higher risk for reoffending (i.e., those considered for SVP commitment but ultimately not committed); therefore, we can develop services to better supervise and monitor this higher risk group. In the long run, such a focus would likely prevent future sexual violence more effectively and more efficiently. 
For instance, some states have at some point developed outpatient SVP schemes (e.g., Texas), whereas other states have specific designations for people deemed at high-risk for committing sex crimes (e.g., Pennsylvania; see Blasko et al., 2011). Programs like these focus resources on outpatient services to monitor and supervise higher risk persons without extensive resources for inpatient SVP commitment. Although in theory these programs appear to address many of the concerns highlighted in inpatient SVP commitment programs, we still know little about their effectiveness at preventing sexual violence. Data from New York State's civil management initiative (i.e., Strict and Intensive Supervision and Treatment [SIST]), which closely monitors those in the community at high risk to reoffend sexually, have been associated with small reductions in sexual rearrest rates and at considerably less cost per client per year (i.e., approximately $\$ 30,000$ per year as compared to $\$ 100,000$ per year; Sandler \& Freeman, 2017). Cross-state comparisons of recidivism rates for states with and without postsentence SVP commitment would offer additional insight into general and relative impact of different sexual violence prevention practices. Indeed, a quasi-experimental comparison of recidivism rates of those at high risk in states without SVP commitment to those in states with SVP commitment (perhaps those nearly committed) might offer a clearer lens for how SVP commitment as a single policy measure contributes to sexual violence reduction efforts. Lave and Zimring (2018) chronicle the story of a California investigation that was shut down after it showed only a $6.5 \%$ recidivism rate for persons committed as SVPs who were later released into the community. If cross-state analyses show similar recidivsm rates for those committed (or nearly committed) as SVPs to others with prior sex offense histories who were never recommended for SVP commitment, then we might reconsider both the value and constitutionality of SVP risk schemes.

\section{Limitations}

The recidivism data analyzed are based upon official records, and national criminal records have previously been criticized for gaps in data. Our decision to define recidivism as 
reconviction for a new crime is a conservative approach that likely underestimates the true number of recidivistic events further. We chose this metric as it represents more of a middle point between two other commonly used measures of recidivism: rearrest and reincarceration. With no universal measure of recidivism, our aim was to provide a metric that might serve as a middle point between more broad (such as victim reports or arrests) and narrow (such as reconviction) definitions of sexual recidivism. Nonetheless, many sex crimes go unreported, authorities may decide not to press charges, charges may be pled down to non-sexual offenses, or there may simply not be sufficient evidence for conviction. Reports by those who have experienced or committed sexual violence, though hampered by issues of reliability, might paint a different picture of recidivism. Further, not all convictions should be considered equally, especially as it pertains to parole violations. For example, lower risk behaviors such as violating curfew and higher risk behaviors such as loitering near schools or parks risk being presented as equally significant violations in broad analysis of convictions. Overall, our recidivism statistics should be considered an underestimate.

Moreover, as with any archival study of this nature, the file data available to use were not collected for research purposes, but rather were maintained in prison files for sentencing, treatment, and management purposes. Specifically, since those who were nearly committed and those that were committed received in-depth psychiatric interviews as part of the commitment process, we had information on diagnoses that may be relevant to SVP civil commitment (e.g., paraphilias and personality disorders) that may not have been gathered for the non-committed sample. Given variation in the type and amount of data available in the file, the analyses were run on subsamples of the entire dataset; extensive missing data analyses (available from the authors) fail to show systematic differences with regard to the types of cases that are missing data. The data also cannot be used to infer the hypothetical recidivism rates of those actually committed as SVPs had they instead been released, as there may be additional differences 
between this group and the nearly committed group which our study design cannot accommodate.

The risk assessment tools analyzed in the current study-the Static-99 and MnSOST-Rhave been replaced with updated versions (the Static-99R and MnSOST-3, respectively) since the timeframe covered in the current data. Data from these instruments better reflect the empirical basis for SVP commitment decisions made at the time; however, they limit the specific recommendations that can be made for current SVP decision-making. Overlaps with the revised versions of these instruments (particularly the substantial overlap between the Static-99 and Static-99R) and trends on the individual risk items assessed in the current study that remain unchanged in the revised instruments suggest similar trends would be observed in an updated study. Nonetheless, some differences in the specifics of empirically based decisions from the timeframe of the study to the present should be acknowledged.

Finally, given the generally low base rate of sexual recidivism ( $5 \%$ in this sample), even with a large sample we may lack power to detect difference among groups. This becomes further problematic when attempting comparisons among smaller sub-samples (e.g., those nearly committed as SVPS or specific offense subtypes). Likewise, we used a proxy sample of nearly committed cases to estimate what might be the recidivism rates of those committed as SVPS. There are, of course, notable differences between these groups. Evaluators had disagreement on the nearly committed group's suitability for commitment (usually not the case for those who were committed), and those nearly committed were ultimately declared safe enough for release (not the case for those who were committed). In addition to our finding that those nearly committed were more likely to have prior sex offenses (a historical risk factor for recidivism) and higher static risk scores compared to others not committed, perhaps those who were committed also elicited additional dynamic risk, verbalized some intent to continue offending, or otherwise demonstrated highly concerning behavior. The recidivism rates for our nearly committed sample may thus underestimate the prospective recidivism of the SVPs. Only 
through some sort of natural experiment, such as a sudden policy change that results in the release of a group of people who were very recently committed as SVPs, might we be able to estimate the expected recidivism rates of those committed as SVPS.

\section{Future Directions}

Further research with proxy samples similar to those committed as SVPS would offer increased insight into who is selected for SVP commitment as well as the prospective recidivism rates of persons targeted for SVP commitment. Consideration of factors beyond static risk scores (e.g., prison-based treatment outcomes, dynamic risk scores) would offer further insight into SVP decision-making, including how states may differentiate commitment recommendations for persons who similarly meet criteria for SVP commitment. Moreover, given that jurisdictions are releasing more people from SVP commitment, multidisciplinary collaborations could model what fraction of sexual violence might be reduced by commitment schemes-and at what cost. Again, integration of dynamic risk would further address decisions not only for SVP commitment but also for the particular timing of release from commitment. As state budgets face increased tightening, such multidisciplinary collaboration could offer legislators and administrators a menu of options and associated costs for each option, promoting evidencebased decision-making while accounting for costs. Economic analysis would also further our understanding of how SVP commitment works within an overall scheme of sexual violence prevention. In addition, to more effectively prevent future sexual violence, policymakers might balance estimated crime prevention associated with SVP commitment with primary prevention techniques and offendse-related treatment services that cast a wider net (see Jeglic \& Calkins, 2016 for review of primary prevention initiatives). 


\section{References}

Associated Press. (2010, June 22). Sex offender confinement costing states too much. http://www.cbsnews.com/stories/2010/06/22/national/main6605890.shtml

Bandler, J., Billig, A., \& Robinson, D. (2017, June 8) Civil commitment: The cost of locking up sex offenders. https://www.lohud.com/story/news/investigations/2017/05/31/civilcommitment-sex-offenders/325390001/

Becker, J. V., Stinson, J., Tromp, S. \& Messer, G. (2003). Characteristics of individuals petitioned for civil commitment. International Journal of Offender Therapy and Comparative Criminology, 47(2), 185-195. https://doi.org/10.1177/0306624Xo3251114

Blasko, B., Jeglic, E. L., \& Mercado, C. C. (2011). Are actuarial risk data used to make determinations of sex offender risk classification? An examination of sex offenders selected for enhanced registration and notification. International Journal of Offender Therapy and Comparative Criminology, 55(5), 676-692. https://doi.org/10.1177/0306624X10372784

Boccaccini, M. T., Murrie, D. C., Caperton, J. D., \& Hawes, S. W. (2009). Field validity of the Static-99 and MnSOST-R among sex offenders evaluated for civil commitment as sexually violent predators. Psychology, Public Policy, and Law, 15(4), 278-314. https://doi.org/10.1037/a0017232

Calkins, C., Jeglic, E., Beattey, R. A., Zeidman, S., \& Perillo, A. D. (2014). Sexual violence legislation: A review of caselaw and empirical research. Psychology, Public Policy, and Law, 20(4), 443-462. https://doi.org/10.1037/law0000027

DeClue, G., \& Rice, A. (2016). Florida's released "Sexually Violent Predators" are not "High Risk.” Open Access Journal of Forensic Psychology, 8, 22-51.

Duwe, G. (2014). To what extent does civil commitment reduce sexual recidivism? Estimating the selective incapacitation effects in Minnesota. Journal of Criminal Justice, 42(2), 193202. http://dx.doi.org/10.1016/j.jcrimjus.2013.06.009

Elwood, R. W. (2019). Agreement between courts and SVP evaluators in the State of Wisconsin. Criminal Justice and Behavior, 46(6), 853-865. https://doi.org/10.1177/0093854819839746

Elwood, R. W., Doren, D. M., \& Thornton, D. (2010). Diagnostic and risk profiles of men detained under Wisconsin's Sexually Violent Person Law. International Journal of Offender Therapy and Comparative Criminology, 54(2), 187-196. https://doi.org/10.1177/0306624X08327305

Epperson, D. L., Kaul, J. D., Huot, S. J., Hesselton, D., Alexander, W., \& Goldman, R. (1998). Minnesota Sex Offender Screening Tool-Revised (MnSOST-R). Minnesota Department of Corrections.

Hanson, R. K. (2002). Recidivism and age: Follow-up data from 4,673 sexual offenders. Journal of Interpersonal Violence, 17(10), 1046-1062. https://doi.org/10.1177/088626002236659

Hanson, R. K., \& Bussière, M. T. (1998). Predicting relapse: A meta-analysis of sexual offender recidivism studies. Journal of Consulting and Clinical Psychology, 66(2), 348-362. https://doi.org/10.1037/0022-006X.66.2.348

Hanson, R. K., \& Morton-Bourgon, K. (2004). Predictors of sexual recidivism: An updated meta-analysis. Public Safety and Emergency Preparedness Canada. https://www.publicsafety.gc.ca/cnt/rsrcs/pblctns/2004-02-prdctrs-sxl-rcdvsmpdtd/2004-02-prdctrs-sxl-rcdvsm-pdtd-eng.pdf

Hanson, R. K., \& Morton-Bourgon, K. E. (2009). The accuracy of recidivism risk assessments for sexual offenders: A meta-analysis. Psychological Assessment, 21(1), 1-21. https://doi.org/10.1037/a0014421 
Hanson, R. K., \& Thornton, D. (1999). Static-99: Improving actuarial risk assessments for sex offenders. Department of the Solicitor General of Canada. http://www.static99.org/pdfdocs/HansonThornton2003.pdf

Harris, A. J. (2015). The civil commitment of sexual predators: A policy review. In R. G. Wright (Ed.), Sex offender laws: Failed policies, new directions (2nd ed., pp. 219-239). Springer Publishing Company.

Jackson, R. L., \& Richards, H. J. (2007). Diagnostic and risk profiles among civilly committed sexual offenders in Washington state. International Journal of Offender Therapy and Comparative Criminology, 51(3), 313-324. https://doi.org/10.1177/0306624X06292874

Janus, E. S., \& Walbeck, N. H. (2000). Sex offender commitments in Minnesota: A descriptive study of second generation commitments. Behavioral Sciences and the Law, 18(2-3), 343374. https://doi.org/10.1002/1099-0798(200003/06)18:2/3<343::AIDBSL395>3.0.CO;2-G

Jeglic, E. L., \& Calkins, C. (Eds.). (2016). Sexual violence: Evidence based policy and prevention. https://doi.org/10.1007/978-3-319-44504-5

Jumper, S., Babula, M., \& Casbon, T. (2012). Diagnostic profiles of civilly committed sexual offenders in Illinois and other reporting jurisdictions: What we know so far. International Journal of Offender Therapy and Comparative Criminology, 56(6), 838-855. https://doi.org/10.1177/0306624X11415509

Kansas v. Hendricks, 521 U.S. 346 (1997). https://www.oyez.org/cases/1996/95-1649

Langton, C. M., Barbaree, H. E., Seto, M. C., Peacock, E. J., Harkins, L., \& Hansen, K. T. (2007). Actuarial assessment of risk for reoffense among adult sex offenders: Evaluating the predictive accuracy of the Static-2002 and five other instruments. Criminal Justice and Behavior, 34(1), 37-59. https://doi.org/10.1177/0093854806291157

Lave, T. R., \& Zimring, F. E. (2018). Assessing the real risk of sexually violent predators: Doctor Padilla's dangerous data. American Criminal Law Review, 55, 705-787.

https://mitchellhamline.edu/sex-offense-litigation-policy/wpcontent/uploads/sites/61/2018/06/Lave-and-Zimring-Assessing-the-Real-Risk-ofSexually-Violent-Predat.pdf

Levenson, J. (2004). Sexual predator civil commitment: A comparison of selected and released offenders. International Journal of Offender Therapy and Comparative Criminology, 48(6), 638-648. https://doi.org/10.1177/0306624X04265089

Levenson, J., \& Morin, J. W. (2006). Factors predicting selection of Sexually Violent Predators for civil commitment. International Journal of Offender Therapy and Comparative Criminology, 5o(6), 609-629. https://doi.org/10.1177/0306624X06287644

Lu, Y., Freeman, N. J., \& Sandler, J. C. (2015). Predictors of the sex offender civil commitment trial outcomes in New York State. Law and Human Behavior, 39(5), 514524. https://doi.org/10.1037/lhboo00143

McLawsen, J. E., Scalora, M. J., \& Darrow, C. (2012). Civilly committed sex offenders: A description and interstate comparison of populations. Psychology, Public Policy, and Law, 18(3), 453-476. https://doi.org/10.1037/a0026116

Mercado, C. C., Bornstein, B. H., \& Schopp, R. F. (2006). Decision-making about volitional impairment in Sexually Violent Predators. Law and Human Behavior, 30(5), 587-602. https://doi.org/10.1007/s10979-006-9055-7

Meyer, W. J., Mollett, M., Richards, C. D., Arnold, L., \& Latham, J. (2003). Outpatient civil commitment in Texas for management and treatment of Sexually Violent Predators: A preliminary report. International Journal of Offender Therapy and Comparative Criminology, 47(4), 396-406. https://doi.org/10.1177/0306624X03253846

Miller, H. A., Amenta, A. E., Conroy, M. A. (2005). Sexually Violent Predator evaluations: Empirical evidence, strategies for professionals, and research directions. Law and Human Behavior, 29(1), 29-54. https://doi.org/10.1007/s10979-005-1398-y 
Milloy, C. (2003). Six-Year Follow-Up of Released Sex Offenders Recommended for Commitment Under Washington's Sexually Violent Predator Law, Where No Petition Was Filed. Washington State Institute for Public Policy. http://www.wsipp.wa.gov/ReportFile/844/Wsipp Six-Year-Follow-Up-of-Released-SexOffenders-Recommended-for-Commitment-Under-Washingtons-Sexually-ViolentPredator-Law-Where-No-Petition-Was-Filed Full-Report.pdf

Milloy, C. (2007). Six-Year Follow-Up of 135 Released Sex Offenders Recommended for Commitment Under Washington's Sexually Violent Predator Law, Where No Petition Was Filed. Washington State Institute for Public Policy. https://www.wsipp.wa.gov/ReportFile/985/Wsipp Six-Year-Follow-Up-of-135-ReleasedSex-Offenders-Recommended-for-Commitment-Under-Washington-s-Sexually-ViolentPredator-Law-Where-No-Petition-Was-Filed Full-Report.pdf

Montaldi, D. (2015). A study of the efficacy of the Sexually Violent Predator Act in Florida. William Mitchell Law Review, 41(3), 781-865.

Neller, D. J., \& Petris, G. (2013). Sexually Violent Predators: Toward reasonable estimates of recidivism base rates. Behavioral Sciences and the Law, 31(4), 429-443. https://doi.org/10.1002/bsl.2072

Nunes, K. L., Firestone P., Bradford, J. M., Greenberg, D. M., \& Broom, I. (2002). A comparison of modified versions of the Static-99 and Sex Offender Risk Appraisal Guide. Sexual Abuse: A Journal of Research and Treatment, 14(3), 253-269. https://doi.org/10.1177/107906320201400305

Office of the Legislative Auditor- State of Minnesota (2011). Civil commitment of sex offenders. Office of the Legislative Auditor. https://www.auditor.leg.state.mn.us/ped/pedrep/ccsosum.pdf

Perillo, A. D., \& Jeglic, E. L. (2013). Sex offender civil commitment costs: How much is too much? Sex Offender Law Report, 14(3), 21-23.

Perillo, A. D., Spada, A. H., Calkins, C., \& Jeglic, E. L. (2014). Examining the scope of questionable diagnostic reliability in Sexually Violent Predator (SVP) evaluations. International Journal of Law and Psychiatry, 37(2), 190-197. https://doi.org/10.1016/j.ijlp.2013.11.005

Sex Offender Civil Commitment Program Network (SOCCPN) (2014). SOCCPN Annual Survey of Sex Offender Civil Commitment Programs 2014. Paper presented at the SOCCPN annual conference, San Diego, CA.

Sandler, J. C., Freeman, N. J., \& Socia, K. M. (2008). Does a watched pot boil? A time- series analysis of New York State's sex offender registration and notification law. Psychology, Public Policy, and Law, 14(4), 284-302. https://doi.org/10.1037/a0013881

Sandler, J. C., \& Freeman, N. J. (2017). Evaluation of New York State's sex offender civil management assessment process recidivism outcomes. Criminology and Public Policy, 16(3), 911-934. https://doi.org/10.1111/1745-9133.12310

Smith, J. M. (2020, June 4). Obscure New Jersey 'treatment' facility has a higher COVID-19 death rate than any prison in the country. Type Investigations. https://www.typeinvestigations.org/investigation/2020/06/04/obscure-new-jerseytreatment-facility-has-a-higher-covid-19-death-rate-than-any-prison-in-the-country/

Vera Institute (2015). Prison spending in 2015. https://www.vera.org/publications/price-ofprisons-2015-state-spending-trends/price-of-prisons-2015-state-spending-trends/price-ofprisons-2015-state-spending-trends-prison-spending

Wrighten, S. A., Al-Barwani, M. B., Moran, R. R., McKee, G. R., \& Dwyer, R. G. (2015). Sexually violent predators and civil commitment: Is selection evidence based? Journal of Forensic Psychiatry \& Psychology, 26(5), 652-666. https://doi.org/10.1080/14789949.2015.1040439 